\title{
Teachers' Opinion About Collaborative Virtual Walls and Massive Open Online Course During the COVID-19 Pandemic
}

\author{
Ricardo-Adán Salas-Rueda ${ }^{{ }^{*}}$ \\ (iD) 0000-0002-4188-4610
}

Gustavo De-La-Cruz-Martínez ${ }^{1}$

(i) 0000-0002-4446-7396

Ana-Libia Eslava-Cervantes ${ }^{1}$

(i) 0000-0002-7420-3412

Ricardo Castañeda-Martínez ${ }^{1}$

(D) 0000-0002-2225-7136

Jesús Ramírez-Ortega ${ }^{1}$

(D) 0000-0002-4538-9203

${ }^{1}$ Instituto de Ciencias Aplicadas y Tecnología, Universidad Nacional Autónoma de México, MEXICO

* Corresponding author: ricardo.salas@icat.unam.mx

Citation: Salas-Rueda, R.-A., De-La-Cruz-Martínez, G., Eslava-Cervantes, A.-L., Castañeda-Martínez, R., \& Ramírez-Ortega, J. (2022). Teachers' Opinion About Collaborative Virtual Walls and Massive Open Online Course During the COVID-19 Pandemic. Online Journal of Communication and Media Technologies, 12(1), e202202. https://doi.org/10.30935/ojcmt/11305

ARTICLE INFO

Received: 24 Jun 2021

Accepted: 29 Sep 2021

\begin{abstract}
During the COVID-19 pandemic, Mexican universities incorporated technological tools to update the activities of the courses under the distance modality. This quantitative research analyzes the teachers' perception about Collaborative Virtual Walls (CVWs) and Massive Open Online Courses (MOOCs) through data science. The participants are 54 professors from the National Autonomous University of Mexico who completed the International Diploma "Innovation in University Teaching 2021". The results of machine learning indicate that CVWs and MOOCs positively influence the learning and participation of the students. Likewise, the decision tree technique identifies 4 predictive models about these technological tools. This study recommends the incorporation of ICTs in the educational field because teachers can organize and carry out creative activities under the distance modality. Even universities can include in their strategic planning the incorporation of CVWs and MOOCs in the educational process. The limitations of this research are the sample and analysis about the perception of the teachers in a Mexican university. Therefore, future research can analyze CVWs and MOOCs considering the development of skills and satisfaction of the students in the middle schools, high schools and universities. In conclusion, teachers rely on technological advances such as CVWs and MOOCs to create new school activities under the distance modality and improve the teaching-learning conditions during the COVID-19 pandemic.
\end{abstract}

Keywords: virtual walls, MOOCs, teachers, data science

\section{INTRODUCTION}

Today, the planning, organization and updating of the courses with the support of technology have great relevance due to the emergence of the COVID-19 pandemic (Beneria et al., 2020; Bergsman \& Chudler, 2021; Chandrasinghe et al., 2020; Colomo-Magaña et al., 2021). In particular, teachers design new school activities under the distance modality in order to facilitate the learning process (Daniel, 2020; Guo \& Zhang, 2017; Zuo et al., 2021). Likewise, universities use CVWs and MOOCs to carry out creative school activities from anywhere (De-Witt \& Koh, 2020; Pottier et al., 2020; Zhu et al., 2020).

Copyright $\odot \mathbf{2 0 2 2}$ by authors; licensee OJCMT. This article is an open access article distributed under the terms and conditions of the Creative Commons Attribution License (http://creativecommons.org/licenses/by/4.0/). 
Information and Communication Technologies (ICTs) allow teachers to build new educational spaces where students actively participate, assimilate the knowledge and develop their skills (Birisci \& Kul, 2019; Chen et al., 2021; García-Peñalvo et al., 2019; Howlett \& Waemusa, 2018). In fact, technological tools are revolutionizing the realization and implementation of the school activities in the 21st century (Colton, 2020; Gambari et al., 2018; Ingulfsen et al., 2018; Zuo et al., 2021). In Mexico, the use of CVWs in the educational field improved the teaching-learning conditions in high schools and universities because the students had an active role before, during and after the face-to-face sessions (Salas-Rueda et al., 2021). In the same way, universities in the United States rely on MOOCs to facilitate the assimilation of knowledge and develop the students' skills from anywhere (Moore \& Wang, 2021).

COVID-19 pandemic caused teachers to update their courses through technological tools such as web platforms, video conferencing systems, CVWs and MOOCs (Boer, 2021; Cahoon et al., 2021; Sangster et al., 2020). CVWs allow students to exchange and share the information of the courses inside and outside the classroom (Andrews et al., 2020; De-Witt \& Koh, 2020; Eiland, 2018). For example, Padlet promotes the active role of the students at any time through the discussion forums (De-Witt \& Koh, 2020; Zou \& Xie, 2019). Likewise, teachers use MOOCs to innovate the learning process and facilitate the assimilation of knowledge (Pérez-Sanagustín et al., 2017; Zhu et al., 2020). Even these technological tools allow the interaction and communication between teachers and students from anywhere (Pottier et al., 2020; Taranto et al., 2020; Zhu et al., 2020).

During the COVID-19 pandemic, Mexican universities incorporated technological tools to update the activities of the courses under the distance modality. This quantitative research analyzes the teachers' perception about CVWs and MOOCs through data science. Therefore, the research questions are:

- What is the perception of the teachers about CVWs and MOOCs during the COVID-19 pandemic?

- What is the impact of CVWs and MOOCs in the learning and participation of the students considering machine learning?

- What are the predictive models about CVWs, MOOCs and the teacher's profile considering the decision tree technique?

\section{LITERATURE REVIEW}

During the COVID-19 pandemic, teachers changed their roles in the educational process (Beneria et al., 2020; Chandrasinghe et al., 2020; Colomo-Magaña et al., 2021; Daniel, 2020). Therefore, technological advances play a fundamental role in the planning, organization, and implementation of new school activities under the distance modality (Beriswill et al., 2016; Kilicer et al., 2018; Pechenkina et al., 2018; Stockleben et al., 2017; Zuo et al., 2021).

\section{Impact of the COVID-19 Pandemic in the Educational Field}

Educational institutions are updating the courses under the distance modality due to the emergence of the COVID-19 pandemic (Boer, 2021; Cahoon et al., 2021; Sangster et al., 2020). Consequently, teachers are incorporating technological tools and web platforms to create new educational virtual spaces (Atiles et al., 2021; Salas-Rueda, 2021; Zhong et al., 2021). For example, the students of tourism used web platforms to interact and communicate with the teacher from anywhere (Zhong et al., 2021).

In the accounting courses, use of flipped classroom and educational web platforms such as Moodle and Google Classroom facilitated the learning process during the COVID-19 pandemic (Sangster et al., 2020). Similarly, the ADDIE pedagogic model and the construction of the JDE application facilitated the assimilation of knowledge and development of skills in the field of electronics (Salas-Rueda, 2021).

Pedagogical models and technological advances improved the teaching-learning conditions about Accounting (Sangster et al., 2020), Electronics (Salas-Rueda, 2021), and Tourism (Zhong et al., 2021) during the COVID pandemic-19. Incorporation of technologies such as CVWs and MOOCs in the school activities allows educational systems to meet the needs of the students through the distance modality (Andrews et al., 2020; Taranto et al., 2020). 


\section{CVWs}

Teachers used CVWs such as Padlet in order to improve the learning process in the courses of the English Language (Zou \& Xie, 2019), Chemistry (Andrews et al., 2020), Social Science (Salas-Rueda et al., 2020), Finance (De-Witt \& Koh, 2020), Medicine (Eiland, 2018), and Geometric Representation Systems (Salas-Rueda et al., 2021). In the English course, the teacher used flipped classroom to update the school activities before, during, and after the face-to-face sessions (Zou \& Xie, 2019). In particular, these students used Padlet to exchange the ideas at any time, encourage the critical thinking, increase the motivation during the learning process and develop their writing skills (Zou \& Xie, 2019).

The benefits of $\mathrm{CVWs}$ are the flexibility of time and space during the teaching-learning process, exchange of the ideas between the participants of the educational process and active role of the students (De-Witt \& Koh, 2020; Zou \& Xie, 2019). In the Finance course, the students improved their academic performance and increased their motivation during the face-to-face sessions through the exchange of the ideas in Padlet (DeWitt \& Koh, 2020).

The incorporation of CVWs in the educational field allows that teachers organize and carry out creative activities inside and outside the classroom (De-Witt \& Koh, 2020; Eiland, 2018; Zou \& Xie, 2019). In Mexico, the use of CVWs facilitated the learning process about Geometric Representation Systems and improved the participation of the students in the classroom through the exchange of the ideas (Salas-Rueda et al., 2021). Similarly, the students at high school used the pedagogical model called "Classroom of the Future", CVWs and mobile devices to discuss the social science topics (Salas-Rueda et al., 2020).

In the Drugs in Pregnancy course, the students used Padlet to actively participate through the discussion forums (Eiland, 2018). Likewise, the teacher of the Chemistry course promoted the collaborative work through the use of this virtual wall (Andrews et al., 2020). Finally, teachers have the opportunity to carry out creative school activities and encourage the participation of the students through CVWs (Andrews et al., 2020; Eiland, 2018).

\section{MOOCs}

Various authors (e.g., Pérez-Sanagustín et al., 2017; Taranto et al., 2020; Zhu et al., 2020) consider that the use of MOOCs in the educational field allows innovating the school activities and facilitate the teachinglearning process. In fact, this technological tool has been used in the universities of Italy (Taranto et al., 2020), Switzerland (De-Castaneda et al., 2015), France (Pottier et al., 2020) and United States (Moore \& Wang, 2021). In the Medicine course, the students improved their academic performance and assimilated the knowledge about health issues at any time through MOOCs (Annaraud \& Singh, 2017).

At the University of Turin, the MOOC called "Math MOOC UniTO" facilitated the communication between the participants of the educational process, assimilation of knowledge about mathematics and development of the skills (Taranto et al., 2020). Similarly, the students of the Medicine course used a MOOC to assimilate the knowledge about the Ebola disease and improve their academic performance (De-Castaneda et al., 2015).

The benefits of MOOCs in the educational field are the development of skills, learning from anywhere, assimilation of knowledge at any time and active role of the students (Pottier et al., 2020; Zhu et al., 2020). In the English as a Foreign Language course, the students developed their communication and grammar skills through MOOCs (Martín-Monje et al., 2018). Also, the students of the Physical course increased their motivation and academic performance through the use of the MOOC called "Super Earths and Life" (Moore \& Wang, 2021).

In France, the students of the Medicine course understood the obesity treatment topics and developed their skills through a MOOC (Pottier et al., 2020). In conclusion, the incorporation of MOOCs in the educational field improved the teaching-learning conditions about Mathematics (Taranto et al., 2020), Medicine (DeCastaneda et al., 2015; Pottier et al., 2020), Health (Annaraud \& Singh, 2017), and Physics (Moore \& Wang, 2021). 

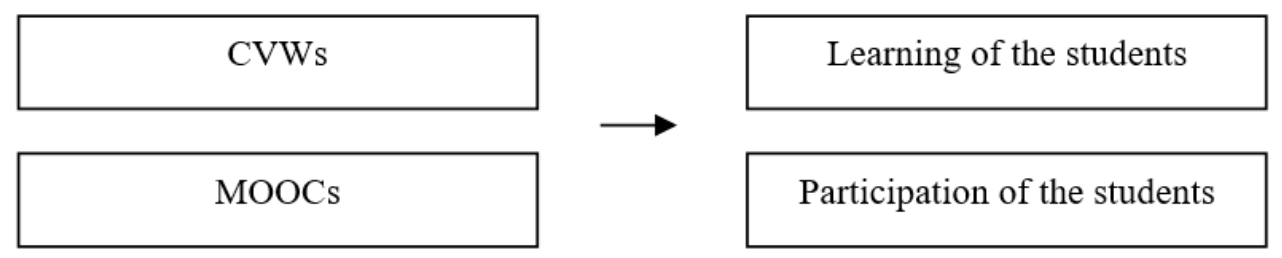

Figure 1. Model used in this quantitative research

\section{METHOD}

The particular aims of this quantitative research are (1) analyze the teachers' perception about CVWs and MOOCs during the COVID-19 pandemic (2) analyze the impact about CVWs and MOOCs in the learning and participation of the students through machine learning (linear regression) and (3) identify the predictive models about CVWs, MOOCs and the teacher's profile through the decision tree technique.

\section{Participants}

The participants are 54 professors (16 men and 38 women) from the National Autonomous University of Mexico who completed the International Diploma "Innovation in University Teaching 2021". These teachers have the academic degree of Bachelor $(n=15,27.78 \%)$, Master $(n=27,50.00 \%)$ and Doctorate $(n=12,22.22 \%)$. Non-probability sampling was used in this study.

\section{Procedure}

During the COVID-19 pandemic, teachers used ICTs in order to carry out the learning process under the distance modality and build new educational spaces. Figure 1 shows the model used to analyze the teachers' perception about CVWs and MOOCs.

Various authors (e.g., Andrews et al., 2020; Eiland, 2018; Zou \& Xie, 2019) mention that CVWs allow the construction of new spaces where students learn and participate during the teaching-learning process. Therefore, the hypotheses about CVWs are:

- Hypothesis $1(\mathrm{H} 1)$ : CVWs positively influence the learning of the students

- Hypothesis $2(\mathrm{H} 2)$ : CVWs positively influence the participation of the students

Likewise, MOOCs improve the teaching-learning conditions and facilitate the active role of students (PérezSanagustín et al., 2017; Pottier et al., 2020; Taranto et al., 2020). Therefore, the hypotheses about MOOCs are:

- Hypothesis $3(\mathrm{H} 3)$ : MOOCs positively influence the learning of the students

- Hypothesis $4(\mathrm{H} 4)$ : MOOCs positively influence the participation of the students

The decision tree technique used the information about the teacher's profile, CVWs and MOOCs to build the following predictive models:

- Predictive Model 1 (PM1) about CVWs and the learning of the students

- Predictive Model 2 (PM2) about CVWs and the participation of the students

- Predictive Model 3 (PM3) about MOOCs and the learning of the students

- Predictive Model 4 (PM4) about MOOCs and the participation of the students

\section{Data Collection}

Table 1 shows the questionnaire used to collect the information during the "Innovation in University Teaching 2021" Diploma.

Table 2 shows the validation of the questionnaire by means of the Load factor, Cronbach's Alpha, Average Variance Extracted and Composite Reliability. 
Table 1. Questionnaire about CVWs and MOOCs

\begin{tabular}{|c|c|c|c|c|c|c|}
\hline No. & Variable & Dimension & Question & Answer & $\mathrm{n}$ & $\%$ \\
\hline \multirow[t]{6}{*}{1} & \multirow{6}{*}{$\begin{array}{l}\text { Profile of } \\
\text { teacher }\end{array}$} & \multirow[t]{2}{*}{ Sex } & \multirow{2}{*}{ 1. What is your sex? } & Man & 16 & $29.63 \%$ \\
\hline & & & & Woman & 38 & $70.37 \%$ \\
\hline & & \multirow{3}{*}{$\begin{array}{l}\text { Maximum } \\
\text { degree of } \\
\text { study }\end{array}$} & \multirow{3}{*}{$\begin{array}{l}\text { 2. What is your maximum } \\
\text { degree of study? }\end{array}$} & Bachelor & 15 & $27.78 \%$ \\
\hline & & & & Master & 27 & $50.00 \%$ \\
\hline & & & & Doctorate & 12 & $22.22 \%$ \\
\hline & & Age & 3. What is your age? & Open & - & - \\
\hline \multirow[t]{16}{*}{2} & \multirow{16}{*}{$\begin{array}{l}\text { Technology in } \\
\text { the educational } \\
\text { field }\end{array}$} & \multirow{4}{*}{ CVWs } & \multirow{4}{*}{$\begin{array}{l}\text { 4. CVWs facilitate the } \\
\text { creation of new school } \\
\text { activities }\end{array}$} & Very much (1) & 26 & $48.15 \%$ \\
\hline & & & & Much (2) & 10 & $18.52 \%$ \\
\hline & & & & Little (3) & 12 & $22.22 \%$ \\
\hline & & & & Very little (4) & 6 & $11.11 \%$ \\
\hline & & \multirow[t]{4}{*}{ MOOCs } & \multirow{4}{*}{$\begin{array}{l}\text { 5. MOOCs facilitate the } \\
\text { creation of new school } \\
\text { activities }\end{array}$} & Very much (1) & 24 & $44.44 \%$ \\
\hline & & & & Much (2) & 11 & $20.37 \%$ \\
\hline & & & & Little (3) & 13 & $24.07 \%$ \\
\hline & & & & Very little (4) & 6 & $11.11 \%$ \\
\hline & & \multirow{4}{*}{$\begin{array}{l}\text { Learning of } \\
\text { the students }\end{array}$} & \multirow{4}{*}{$\begin{array}{l}\text { 6. The use of technology } \\
\text { facilitates the learning of } \\
\text { the students }\end{array}$} & Very much (1) & 37 & $68.52 \%$ \\
\hline & & & & Much (2) & 10 & $18.52 \%$ \\
\hline & & & & Little (3) & 7 & $12.96 \%$ \\
\hline & & & & Very little (4) & 0 & $0.00 \%$ \\
\hline & & \multirow{4}{*}{$\begin{array}{l}\text { Participation } \\
\text { of the } \\
\text { students }\end{array}$} & \multirow{4}{*}{$\begin{array}{l}\text { 7. The use of technology } \\
\text { facilitates the } \\
\text { participation of the } \\
\text { students }\end{array}$} & Very much (1) & 36 & $66.67 \%$ \\
\hline & & & & Much (2) & 13 & $24.07 \%$ \\
\hline & & & & Little (3) & 5 & $9.26 \%$ \\
\hline & & & & Very little (4) & 0 & $0.00 \%$ \\
\hline
\end{tabular}

Table 2. Validation of the questionnaire

\begin{tabular}{lllccc}
\hline Variable & Dimension & Load factor & $\begin{array}{c}\text { Cronbach's } \\
\text { Alpha }\end{array}$ & $\begin{array}{c}\text { Average Variance } \\
\text { Extracted }\end{array}$ & $\begin{array}{c}\text { Composite } \\
\text { Reliability }\end{array}$ \\
\hline Technology in the & CVWs & 0.652 & & & 0.807 \\
educational field & MOOCs & 0.718 & 0.659 & 0.513 & \\
& Learning & 0.726 & & & \\
& Participation & 0.765 & & & \\
\hline
\end{tabular}

\section{Data Analysis}

This research used the free RapidMiner tool to analyze the teachers' perception about CVWs and MOOCs through data science (machine learning and decision tree techniques). This application can be downloaded at https://rapidminer.com/

The RapidMiner tool allowed calculating machine learning (linear regressions) to evaluate the hypotheses about CVWs and MOOCs. The training section with $50 \%(n=27), 60 \%(n=32)$, and $70 \%(n=38)$ of the sample allowed the calculation of the linear regressions and the evaluation section with $50 \%(n=27), 40 \%(n=22)$, and $30 \%(n=16)$ of the sample allowed establishing the accuracy of these regressions by means of the squared error.

On the other hand, the information about the teacher's profile (sex, age and maximum degree of study), CVWs and MOOCs allow the construction of the predictive models through the decision tree technique.

\section{RESULTS}

The use of technology facilitates very much $(n=37,68.52 \%)$, much $(n=10,18.52 \%)$, and little $(n=7,12.96 \%)$ the learning of the students (See Table 1). Likewise, the use of technology facilitates very much $(n=36,66.67 \%)$, much $(n=13,24.07 \%)$, and little $(n=5,9.26 \%)$ the participation of the students. Also, the results of machine learning indicate that CVWs and MOOCs positively influence the learning and participation of the students (See Table 3). 
Table 3. Results of machine learning

\begin{tabular}{lllllcc}
\hline Hypothesis & Training & Linear regression & Conclusion & t-value & p-value & Squared error \\
\hline H1: CVWs $\rightarrow$ & $50 \%$ & $y=0.289 x+0.897$ & Accepted: 0.289 & 2.341 & 0.027 & 0.649 \\
learning of the & $60 \%$ & $y=0.316 x+0.814$ & Accepted: 0.316 & 3.062 & 0.004 & 0.817 \\
students & $70 \%$ & $y=0.283 x+0.910$ & Accepted: 0.283 & 2.926 & 0.005 & 0.863 \\
\hline H2: CVWs $\rightarrow$ & $50 \%$ & $y=0.305 x+0.751$ & Accepted: 0.305 & 2.833 & 0.009 & 0.544 \\
participation of the & $60 \%$ & $y=0.313 x+0.726$ & Accepted: 0.313 & 3.494 & 0.001 & 0.677 \\
students & $70 \%$ & $y=0.297 x+0.778$ & Accepted: 0.297 & 3.863 & 0.000 & 0.848 \\
\hline H3: MOOCs $\rightarrow$ & $50 \%$ & $y=0.192 x+1.091$ & Accepted: 0.192 & 1.560 & 0.131 & 0.490 \\
learning of the & $60 \%$ & $y=0.204 x+1.003$ & Accepted: 0.204 & 1.893 & 0.068 & 0.564 \\
students & $70 \%$ & $y=0.260 x+0.905$ & Accepted: 0.260 & 2.759 & 0.009 & 0.660 \\
\hline H4: MOOCs $\rightarrow$ & $50 \%$ & $y=0.115 x+1.149$ & Accepted: 0.115 & 1.009 & 0.322 & 0.419 \\
participation of the & $60 \%$ & $y=0.130 x+1.066$ & Accepted: 0.130 & 1.304 & 0.201 & 0.504 \\
students & $70 \%$ & $y=0.178 x+0.971$ & Accepted: 0.178 & 2.143 & 0.038 & 0.648 \\
\hline
\end{tabular}

Table 4. Pearson correlations

\begin{tabular}{lcccc}
\hline & CVWs & MOOCs & Learning & Participation \\
\hline CVWs & 1 & - & - & - \\
MOOCs & 0.456 & 1 & - & - \\
Learning & 0.192 & 0.308 & 1 & - \\
Participation & 0.286 & 0.308 & 0.547 & 1 \\
\hline
\end{tabular}

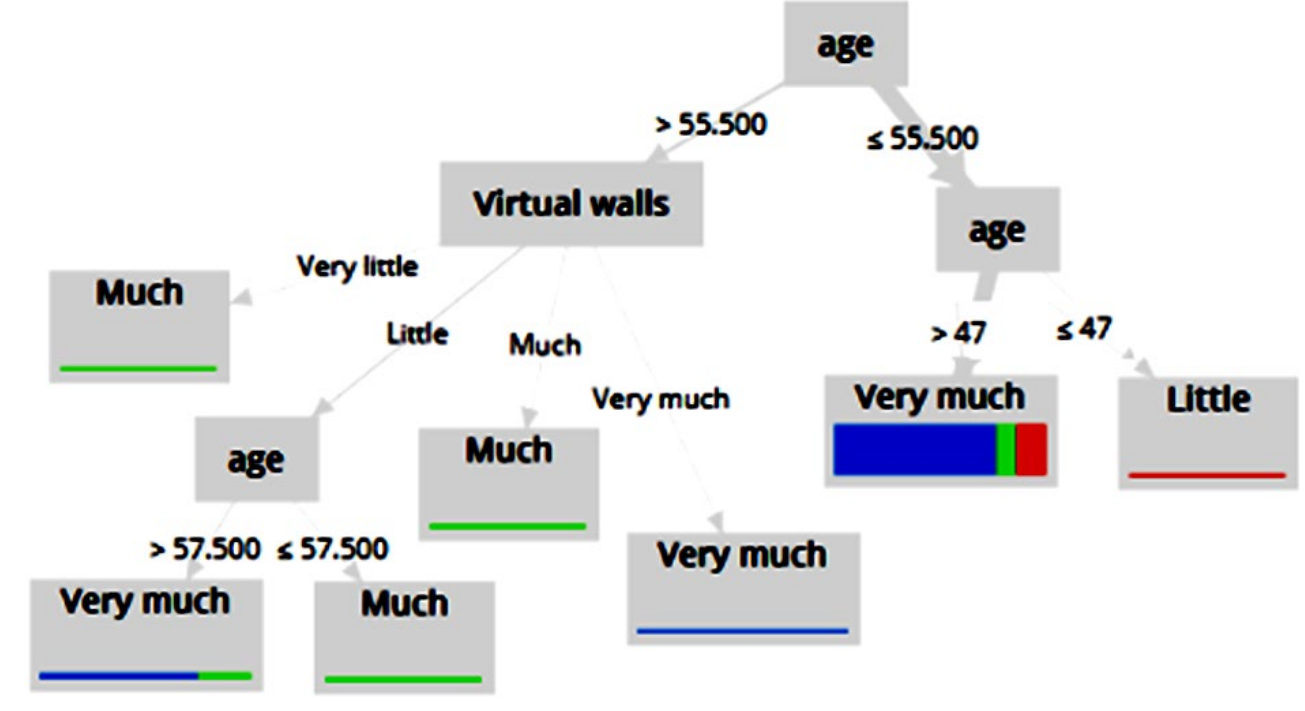

Figure 2. PM1 about CVWs

Table 4 shows the Pearson's correlations about CVWs, MOOCs, learning and participation of the students.

\section{CVWs}

CVWs facilitate very much $(n=26,48.15 \%)$, much $(n=10,18.52 \%)$, little $(n=12,22.22 \%)$, and very little $(n=$ $6,11.11 \%)$ the creation of new school activities (See Table 1). The results of machine learning with $50 \%(0.289$, t_value $=2.341$, p_value $=0.027), 60 \%(0.316$, t_value $=3.062$, p_value $=0.004)$ and $70 \%(0.283$, t_value $=2.926$, p_value $=0.005$ ) of training indicate that $\mathrm{H} 1$ is accepted (See Table 3 ). Therefore, CVWs positively influence the learning of the students.

Figure 2 shows 7 conditions of the PM1 with the accuracy of 79.63\%. For example, if the teacher considers that CVWs facilitate very much the creation of new school activities and has an age $>55.5$ years then the use of technology facilitates very much the learning of the students. On the other hand, if the teacher considers that CVWs facilitate much the creation of new school activities and has an age $>55.5$ years then the use of technology facilitates much the learning of the students. 


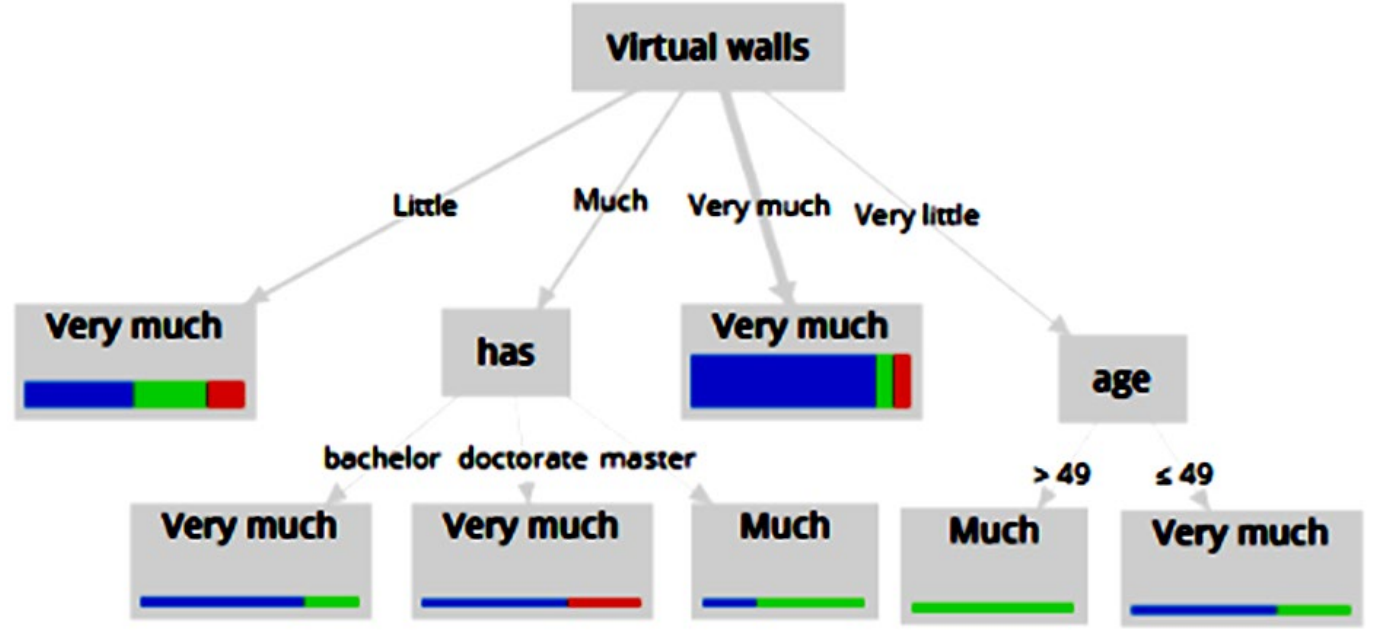

Figure 3. PM2 about CVWs

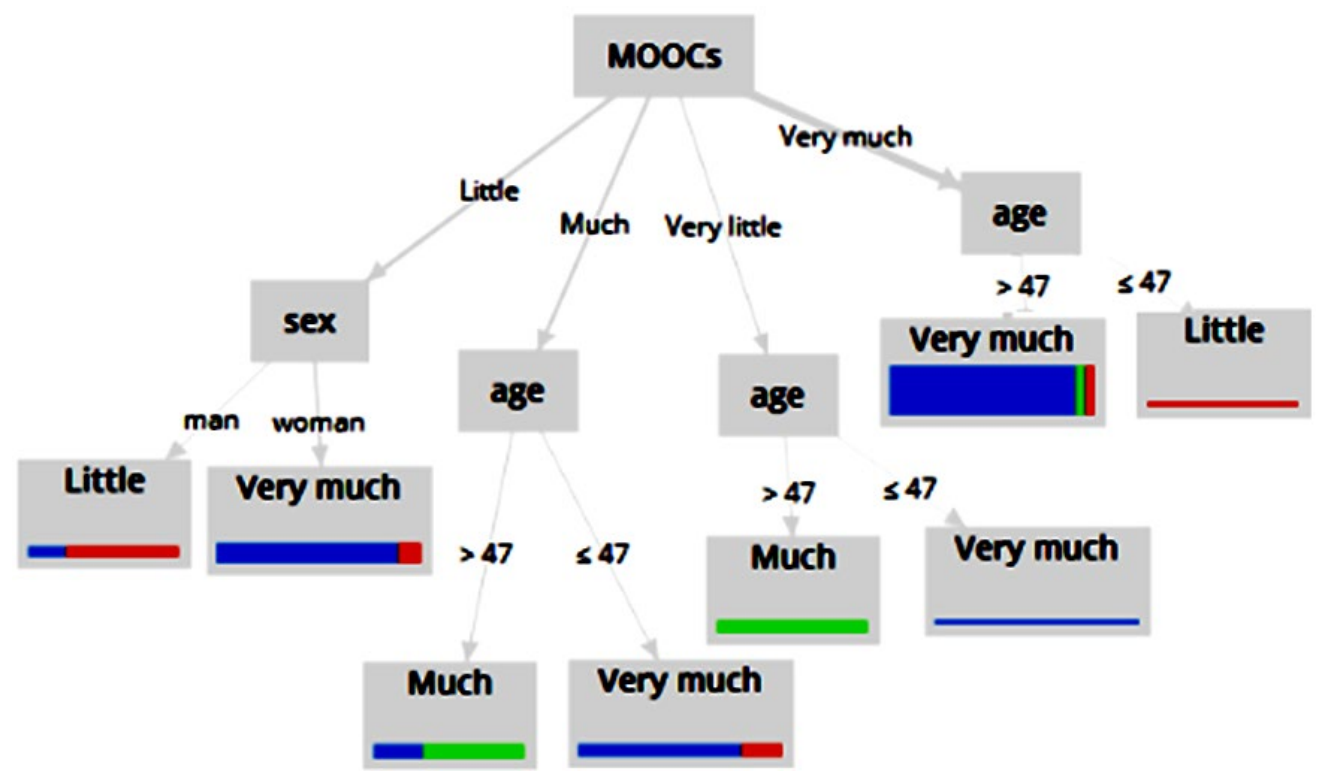

Figure 4. PM3 about MOOCs

The results of machine learning with $50 \%(0.305, \mathrm{t}$-value $=2.833$, p_value $=0.009), 60 \%(0.313, \mathrm{t}$ _value $=$ 3.494 , p_value $=0.001)$ and $70 \%\left(0.297\right.$, t_value $=3.863, p_{-}$value $\left.=0.000\right)$ of training indicate that $\mathrm{H} 2$ is accepted (See Table 3). Therefore, CVWs positively influence the participation of the students.

Figure 3 shows 7 conditions of the PM2 with the accuracy of $74.07 \%$. For example, if the teacher considers that CVWs facilitate much the creation of new school activities and has the doctorate then the use of technology facilitates very much the participation of the students. On the other hand, if the teacher considers that CVWs facilitate much the creation of new school activities and has the master then the use of technology facilitates much the participation of the students.

\section{MOOCs}

MOOCs facilitate very much $(n=24,44.44 \%)$, much $(n=11,20.37 \%)$, little $(n=13,24.07 \%)$, and very little ( $n$ $=6,11.11 \%$ ) the creation of new school activities (See Table 1). The results of machine learning with $50 \%$ $(0.192$, t_value $=1.560$, p_value $=0.131), 60 \%(0.204$, t_value $=1.893$, p_value $=0.068)$ and $70 \%(0.260$, t_value $=2.759$, p_value $=0.009$ ) of training indicate that $\mathrm{H} 3$ is accepted (See Table 3 ). Therefore, MOOCs positively influence the learning of the students.

Figure 4 shows 8 conditions of the PM3 with the accuracy of $87.04 \%$. For example, if the teacher considers that MOOCs facilitate very much the creation of new school activities and has an age $>47$ years then the use 


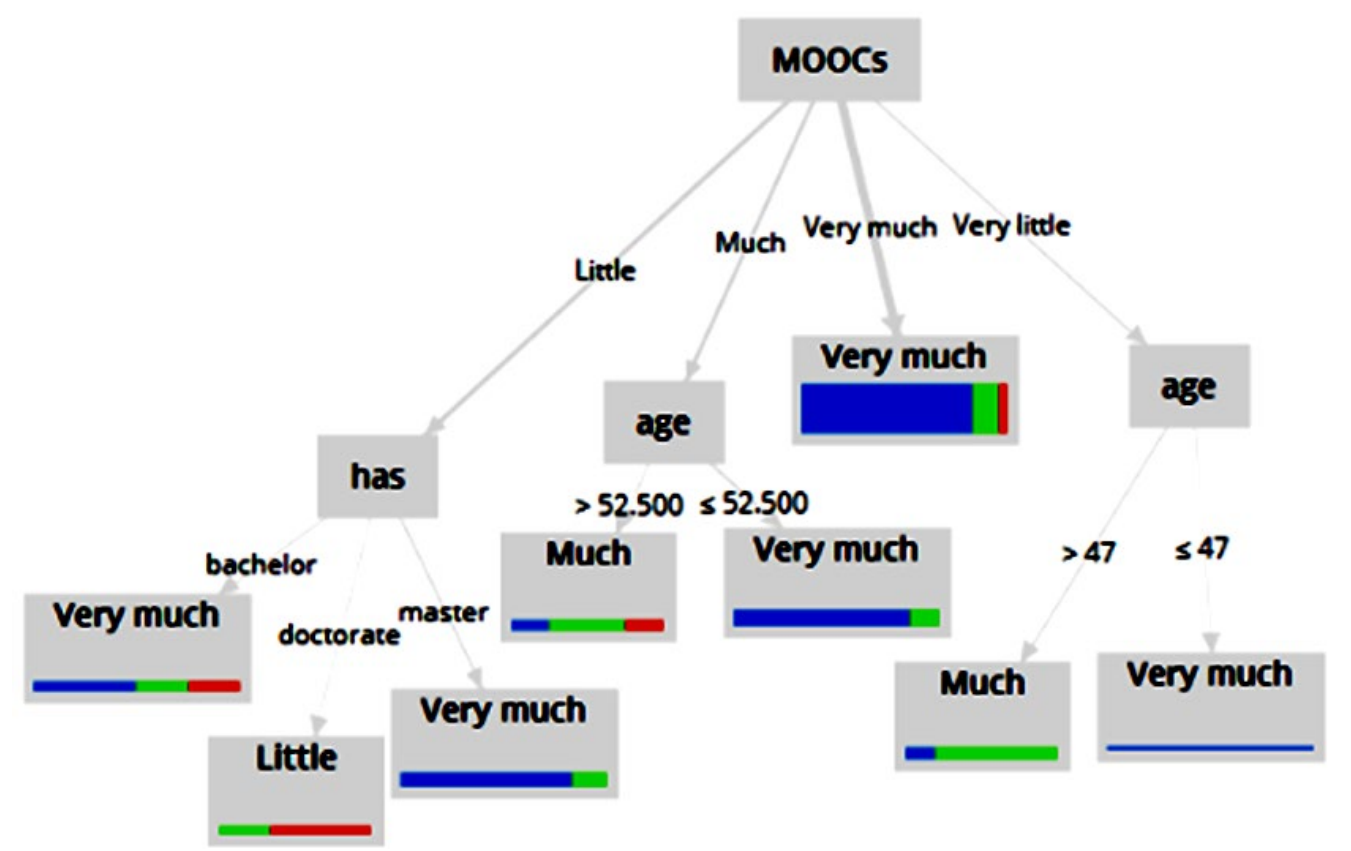

Figure 5. PM4 about MOOCs

of technology facilitates very much the learning of the students. On the other hand, if the teacher considers that MOOCs facilitate much the creation of new school activities and has an age $>47$ years then the use of technology facilitates much the learning of the students.

The results of machine learning with $50 \%\left(0.115, t_{-}\right.$value $=1.009, p_{-}$value $\left.=0.322\right), 60 \%\left(0.130, t_{-}\right.$value $=$ 1.304 , p_value $=0.201)$, and $70 \%\left(0.178, t_{\text {_value }}=2.143, \mathrm{p}_{\text {_value }}=0.038\right)$ of training indicate that $\mathrm{H} 4$ is accepted (See Table 3). Therefore, MOOCs positively influence the learning of the students.

Figure 5 shows 8 conditions of the PM4 with an accuracy of $77.78 \%$. For example, if the teacher considers that MOOCs facilitate much the creation of new school activities and has an age $>52.5$ years then the use of technology facilitates much the participation of the students. On the other hand, if the teacher considers that MOOCs facilitate very much the creation of new school activities then the use of technology facilitates very much the participation of the students.

\section{DISCUSSION}

Various authors (e.g., Chen et al., 2021; Hava \& Gelibolu, 2018; Ingulfsen et al., 2018; Parra et al., 2019) mention that teachers use ICTs to carry out creative activities and build new virtual spaces for learning. As a result of the analysis performed, $68.52 \%$ of the teachers $(n=37)$ consider that the use of technology facilitates very much the learning of the students. Likewise, the use of technology facilitates much $(n=10,18.52 \%)$ the learning of the students. Consequently, majority of the teachers (87.04\%) have a favorable opinion about this aspect. Likewise, this study shares the ideas of various authors (e.g., Boer, 2021; Cahoon et al., 2021) about the incorporation of technological tools in the school activities to meet the needs of the students during the COVID-19 pandemic.

Educational institutions promote the active role of the students during the teaching-learning process through the use of ICTs (García-Peñalvo et al., 2019; Moore \& Wang, 2021; Stockleben et al., 2017). In particular, $66.67 \%$ of the teachers $(n=36)$ consider that the use of technology facilitates very much the participation of the students. Analysis showed that the use of technology facilitates much $(n=13,24.07 \%)$ the participation of the students. Consequently, the majority of teachers (90.74\%) have a favorable opinion about this aspect. This research confirms the findings of various authors (e.g., Cahoon et al., 2021; Boer, 2021) about the use of ICTs to promote the active role of students. 


\section{CVWs}

Today, teachers use virtual walls to facilitate the learning process, develop the skills and encourage the participation of the students (Andrews et al., 2020; De-Witt \& Koh, 2020; Eiland, 2018; Zou \& Xie, 2019). As a result of the analysis performed, $48.15 \%$ of the teachers $(n=26)$ consider that CVWs facilitate very much the creation of new school activities. Also, CVWs facilitate much $(\mathrm{n}=10,18.52 \%)$ the creation of new school activities. Therefore, the majority of the teachers (66.67\%) have a favorable opinion about this technological tool.

Similar to Zou and Xie (2019), the use of the virtual wall improved the teaching-learning conditions through the exchange of the ideas. The results of machine learning about $\mathrm{H} 1$ are higher than 0.280 , therefore, CVWs positively influence the learning of the students. Consequently, the teachers at the National Autonomous University of Mexico consider that this technological tool improves the teaching-learning conditions during the COVID-19 pandemic.

Data science identified 7 conditions of the PM1 where the age of the teacher determines how virtual walls influence the learning. In fact, the decision tree technique presents 3 conditions where the use of technology facilitates very much the learning of the students. For example, if the teacher considers that CVWs facilitate very much the creation of new school activities and has an age > 55.5 years then the use of technology facilitates very much the learning of the students.

Also, data science presents 3 conditions where the use of technology facilitates much the learning of the students. For example, if the teacher considers that CVWs facilitate much the creation of new school activities and has an age > 55.5 years then the use of technology facilitates much the learning of the students. Finally, this model presents 1 condition where the use of technology facilitates little the learning of the students.

This research shares the ideas of various authors (e.g., Andrews et al., 2020; De-Witt \& Koh, 2020; Zou \& Xie, 2019) about the use of virtual walls to facilitate the active role of the students inside and outside the classroom. The results of machine learning about $\mathrm{H} 2$ are higher than 0.290 , therefore, CVWs positively influence the participation of the students. Consequently, this technological tool favors the teaching-learning conditions during the COVID-19 pandemic.

Data science identified 7 conditions of the PM2 where the age and educational level of the teacher determine how virtual walls influence the participation of the students. In fact, the decision tree technique presents 5 conditions where the use of technology facilitates very much the participation of the students. For example, if the teacher considers that CVWs facilitate much the creation of new school activities and has the doctorate then the use of technology facilitates very much the participation of the students.

Also, data science presents 2 conditions where the use of technology facilitates much the participation of the students. For example, if the teacher considers that CVWs facilitate much the creation of new school activities and has the master then the use of technology facilitates much the participation of the students.

\section{MOOCs}

Various authors (e.g., De-Castaneda et al., 2015; Guo \& Zhang, 2017; Moore \& Wang, 2021) mention that MOOCs facilitate the assimilation of knowledge and development of skills under the distance modality. In particular, $44.44 \%$ of the teachers $(n=24)$ think that MOOCs facilitate very much the creation of new school activities. Also, MOOCs facilitate much $(n=11,20.37 \%)$ the creation of new school activities. Consequently, the majority of the teachers (64.81\%) have a favorable opinion about this technological tool.

As mentioned by Taranto et al. (2020), the incorporation of MOOCs in the educational field facilitates the teaching-learning process at any time. The results of machine learning about H3 are higher than 0.190, therefore, MOOCs positively influence the learning of the students. Consequently, the teachers at the National Autonomous University of Mexico consider that this technological tool improves the teaching-learning conditions during the COVID-19 pandemic.

Data science identified 8 conditions of the PM3 where the age and sex of the teacher determine how MOOCs influence the learning. In fact, the decision tree technique presents 4 conditions where the use of technology facilitates very much the learning of the students. For example, if the teacher considers that 
MOOCs facilitate very much the creation of new school activities and has an age $>47$ years then the use of technology facilitates very much the learning of the students.

Also, data science presents 2 conditions where the use of technology facilitates much the learning of the students. For example, if the teacher considers that MOOCs facilitate much the creation of new school activities and has an age $>47$ years then the use of technology facilitates much the learning of the students. Finally, this model presents 2 conditions where the use of technology facilitates little the learning of the students. For example, if the teacher considers that MOOCs facilitate little the creation of new school activities and is a man then the use of technology facilitates little the learning of the students.

Also, students use MOOCs to facilitate the assimilation of knowledge and actively participate during the teaching-learning process (De-Castaneda et al., 2015; Moore \& Wang, 2021; Zhu et al., 2020). The results of machine learning about $\mathrm{H} 4$ are higher than 0.110 , therefore, MOOCs positively influence the participation of the students. Consequently, this technological tool favors the teaching-learning conditions during the COVID19 pandemic.

Data science identified 8 conditions of the PM4 where the age and educational level of the teacher determine how MOOCs influence the participation of the students. In fact, the decision tree technique presents 5 conditions where the use of technology facilitates very much the participation of the students. For example, if the teacher considers that MOOCs facilitate very much the creation of new school activities then the use of technology facilitates very much the participation of the students.

Also, data science presents 2 conditions where the use of technology facilitates much the participation of the students. For example, if the teacher considers that MOOCs facilitate much the creation of new school activities and has an age > 52.5 years then the use of technology facilitates much the participation of the students. Finally, this model presents 1 condition where the use of technology facilitates little the participation of the students. For example, if the teacher considers that MOOCs facilitate little the creation of new school activities and has the doctorate then the use of technology facilitates little the participation of the students.

\section{CONCLUSION}

Educational institutions are changing the teaching-learning process with the support of technological tools due to the emergence of COVID-19. In particular, the results of machine learning indicate that CVWs and MOOCs positively influence the learning and participation of the students.

This study recommends the incorporation of ICTs in the educational field because teachers can organize and carry out creative activities under the distance modality. In particular, educational institutions can include in their strategic planning the use of CVWs and MOOCs during the teaching-learning process.

The limitations of this research are the sample and analysis about the perception of the teachers in a Mexican university. Therefore, future research can analyze CVWs and MOOCs considering the development of skills and satisfaction of the students in the middle schools, high schools and universities.

The implications of this study allow that teachers use CVWs to facilitate the learning and promote the active role of the students through the exchange of ideas from any place. Likewise, the incorporation of MOOCs in the educational field facilitates the organization and realization of creative activities under the distance modality.

In conclusion, the COVID-19 pandemic is transforming the roles of the teachers and students during the educational process. Therefore, CVWs and MOOCs allow the construction of new virtual spaces in order to meet the educational demands in the 21 st century.

Author contributions: All authors were involved in concept, design, collection of data, interpretation, writing, and critically revising the article. All authors approve final version of the article.

Funding: This work was supported by UNAM-DGAPA-PAPIME: El Aula del Futuro de la Escuela Nacional Preparatoria 2 (PE208721), El Aula del Futuro de la Escuela Nacional Preparatoria 6 (PE106221), El Aula del Futuro de la Escuela Nacional Preparatoria 8 (PE308221) and El Aula del Futuro de la Facultad de Artes y Diseño (PE402721).

Declaration of interest: Authors declare no competing interest.

Data availability: Data generated or analysed during this study are available from the authors on request. 


\section{REFERENCES}

Annaraud, K., \& Singh, D. (2017). Perceptions of hospitality faculty and students of Massive Open Online Courses (MOOCs). Journal of Hospitality \& Tourism Education, 29(2), 82-90. https://doi.org/10.1080/10963758.2017.1297714

Andrews, D. A., Sekyere, E. O., \& Bugarcic, A. (2020). Collaborative active learning activities promote deep learning in a chemistry-biochemistry course. Medical Science Educator, 30, 801-810. https://doi.org/10.1007/s40670-020-00952-x

Atiles, J. T., Almodóvar, M., Chavarría-Vargas, A., Dias, M. J., \& Zúñiga-León, I. M. (2021). International responses to COVID-19: challenges faced by early childhood professionals. European Early Childhood Education Research Journal, 29(1), 66-78. https://doi.org/10.1080/1350293X.2021.1872674

Beneria, A., Arnedo, M., Contreras, S., \& Pérez-Carrasco, M. (2020). Impact of simulation-based teamwork training on COVID-19 distress in healthcare professionals. BMC Medical Education, 20, 515. https://doi.org/10.1186/s12909-020-02427-4

Beriswill, J. E., Bracey, P. S., Sherman-Morris, K., \& Huang, K. (2016). Professional development for promoting 21 st century skills and common core state standards in foreign language and social studies classrooms. TechTrends, 60, 77-84. https://doi.org/10.1007/s11528-015-0004-5

Bergsman, K. C., \& Chudler, E. H. (2021). Adapting a neural engineering summer camp for high school students to a fully online experience. Biomedical Engineering Education, 1, 37-42. https://doi.org/10.1007/s43683020-00011-2

Birisci, S., \& Kul, E. (2019). Predictors of technology integration self-efficacy beliefs of preservice teachers. Contemporary Educational Technology, 10(1), 75-93. https://doi.org/10.30935/cet.512537

Boer, H. D. (2021). COVID-19 in Dutch higher education. Studies in Higher Education, 46(1), 96-106. https://doi.org/10.1080/03075079.2020.1859684

Cahoon, A., McGill, S., \& Simms, V. (2021). Understanding home education in the context of COVID-19 lockdown. Irish Educational Studies, 40(2), 443-455. https://doi.org/10.1080/03323315.2021.1921010

Chandrasinghe, P. C., Siriwardana, R.C., Kumarage, S. K., \& Munasinghe, B. N. (2020). A novel structure for online surgical undergraduate teaching during the COVID-19 pandemic. BMC Medical Education, 20, 324 (2020). https://doi.org/10.1186/s12909-020-02236-9

Chen, W., Tan, J. S., \& Pi, Z. (2021). The spiral model of collaborative knowledge improvement: an exploratory study of a networked collaborative classroom. International Journal of Computer-Supported Collaborative Learning, 16, 7-35. https://doi.org/10.1007/s11412-021-09338-6

Colomo-Magaña, E., Cívico-Ariza, A., Ruiz-Palmero, J., \& Sánchez-Rivas, E. (2021). Problematic use of ICTs in trainee teachers during COVID-19: A sex-based analysis. Contemporary Educational Technology, 13(4), ep314. https://doi.org/10.30935/cedtech/10988

Colton, J. (2020). Social, innovative and deep: Exploring digital literacies in a year 9 English classroom. Changing English, 27(3), 270-284. https://doi.org/10.1080/1358684X.2020.1766946

Daniel, S. J. (2020). Education and the COVID-19 pandemic. Prospects, 49, 91-96. https://doi.org/10.1007/s11125-020-09464-3

De-Castaneda, R. R., Valticos, A., Pittet, D., \& Flahault, A. (2015). MOOCs (massive online open courses) as innovative tools in education in infection prevention and control: Reflections from the first MOOC on Ebola. Antimicrobial Resistance and Infection Control, 1-16. https://doi.org/10.1186/2047-2994-4-S1-016

De-Witt, D., \& Koh, E. H. (2020). Promoting knowledge management processes through an interactive virtual wall in a postgraduate business finance course. Journal of Education for Business, 95(4), $255-262$. https://doi.org/10.1080/08832323.2019.1635977

Eiland, L. S. (2018). Student perceptions of active-learning strategies utilized in a drugs in pregnancy elective delivered synchronously across multiple campuses. TechTrends, 62, 259-265. https://doi.org/10.1007/s11528-018-0260-2

García-Peñalvo, F. J., Vázquez-Ingelmo, A., García-Holgado, A., \& Seoane-Pardo, A. M. (2019). Analyzing the usability of the WYRED Platform with undergraduate students to improve its features. Universal Access in the Information Society, 18, 455-468. https://doi.org/10.1007/s10209-019-00672-z 
Gambari, A. I., Kawu, H., \& Falode, O. C. (2018). Impact of virtual laboratory on the achievement of secondary school chemistry students in homogeneous and heterogeneous collaborative environments. Contemporary Educational Technology, 9(3), 246-263. https://doi.org/10.30935/cet.444108

Guo, S., \& Zhang, G. (2017). Analyzing concept complexity, knowledge ageing and diffusion pattern of Mooc. Scientometrics, 112, 413-430. https://doi.org/10.1007/s11192-017-2385-z

Hava, K., \& Gelibolu, M. F. (2018). The impact of digital citizenship instruction through flipped classroom model on various variables. Contemporary Educational Technology, 9(4), 390-404. https://doi.org/10.30935/cet.471013

Howlett, G., \& Waemusa, Z. (2018). Digital native/digital immigrant divide: EFL teachers' mobile device experiences and practice. Contemporary Educational Technology, 9(4), 374-389. https://doi.org/10.30935/cet.471007

Ingulfsen, L., Furberg, A., \& Stromme, T. A. (2018). Students' engagement with real-time graphs in CSCL settings: scrutinizing the role of teacher support. International Journal of Computer-Supported Collaborative Learning, 13, 365-390. https://doi.org/10.1007/s11412-018-9290-1

Kilicer, K., Bardakci, S., \& Arpaci, I. (2018). Investigation of emerging technology usage characteristics as predictors of innovativeness. Contemporary Educational Technology, 9(3), 225-245. https://doi.org/10.30935/cet.444100

Martín-Monje, E., Castrillo, M. D., \& Mañana-Rodríguez, J. (2018). Understanding online interaction in language MOOCs through learning analytics. Computer Assisted Language Learning, 31(3), 251-272. https://doi.org/10.1080/09588221.2017.1378237

Moore, R. L., \& Wang, C. (2021). Influence of learner motivational dispositions on MOOC completion. Journal of Computing in Higher Education, 33, 121-134. https://doi.org/10.1007/s12528-020-09258-8

Parra, J., Raynor, C., Osanloo, A., \& Guillaume, R. O. (2019). (Re)imagining an undergraduate integrating technology with teaching course. TechTrends, 63, 68-78. https://doi.org/10.1007/s11528-018-0362-x

Pechenkina, E., Scardamaglia, A., \& Gregory, J. (2018). "It's the combination that works": Evaluating student experiences with a multi-element blended design in first-year law. Contemporary Educational Technology, 9(4), 405-422. https://doi.org/10.30935/cet.471019

Pérez-Sanagustín, M., Hilliger, I., Alario-Hoyos, C., \& Delgado-Kloos, C. (2017). H-MOOC framework: Reusing MOOCs for hybrid education. Journal of Computing in Higher Education, 29, 47-64. https://doi.org/10.1007/s12528-017-9133-5

Pottier, E., Boulanouar, L., Bertrand, M., \& Estrade, A. (2020). A MOOC about bariatric surgery improves knowledge and promotes patients' soft skills. Obesity Surgery, 30, 1600-1604. https://doi.org/10.1007/s11695-019-04143-5

Salas-Rueda, R. A. (2021). Students' perception of the design and usability of the Digital Game for the teachinglearning process about Electronics version 1.0. Revista Electrónica sobre Ciencia, Tecnología y Sociedad, 8(15), 1-15.

Salas-Rueda, R. A., De-La-Cruz-Martínez, G., Alvarado-Zamorano, C., \& Gamboa-Rodríguez, F. (2020). Mobile devices and collaborative wall: Media to innovate the teaching learning process on social sciences? Meta: Avaliacao, 12(36), 601-624.

Salas-Rueda, R. A., Ramírez-Ortega, J., \& Eslava-Cervantes, A. L. (2021). Use of the collaborative wall to improve the teaching-learning conditions in the bachelor of visual arts. Contemporary Educational Technology, 13(1), ep286. https://doi.org/10.30935/cedtech/8711

Sangster, A., Stoner, G., \& Flood, B. (2020). Insights into accounting education in a COVID-19 world. Accounting Education, 29(5), 431-562. https://doi.org/10.1080/09639284.2020.1808487

Stockleben, B., Thayne, M., Jaminki, S., \& Haukijarvi, I. (2017). Towards a framework for creative online collaboration: A research on challenges and context. Education and Information Technologies, 22, 575597. https://doi.org/10.1007/s10639-016-9483-z

Taranto, E., Robutti, O., \& Arzarello, F. (2020). Learning within MOOCs for mathematics teacher education. ZDM Mathematics Education, 52, 1439-1453. https://doi.org/10.1007/s11858-020-01178-2

Zhong, Y. Y., Busser, J., Shapoval, V., \& Murphy, K. (2021). Hospitality and tourism student engagement and hope during the COVID-19 pandemic. Journal of Hospitality \& Tourism Education, 33(3), 194-206. https://doi.org/10.1080/10963758.2021.1907197 
Zhu, M., Sari, A. R., \& Lee, M. M. (2020). A comprehensive systematic review of MOOC research: Research techniques, topics, and trends from 2009 to 2019. Educational Technology Research and Development, 68, 1685-1710. https://doi.org/10.1007/s11423-020-09798-x

Zou, D., \& Xie, H. (2019). Flipping an English writing class with technology-enhanced just-in-time teaching and peer instruction. Interactive Learning Environments, 27(8), 1127-1142. https://doi.org/10.1080/10494820.2018.1495654

Zuo, M., Ma, Y., Hu, Y., \& Luo, H. (2021). K-12 students' online learning experiences during COVID-19: Lessons from China. Frontiers of Education in China, 16, 1-30. https://doi.org/10.1007/s11516-021-0001-8

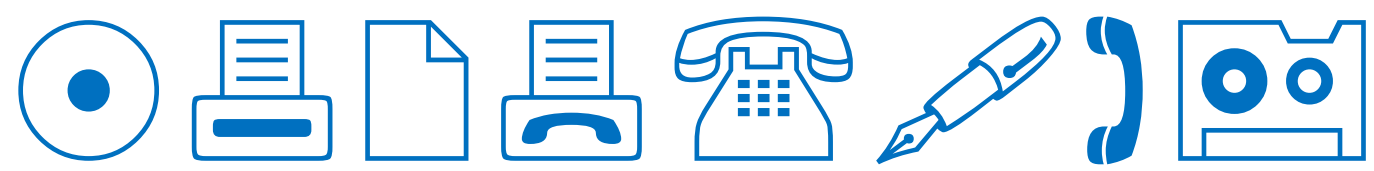

